\title{
PRODUTIVIDADE DE HÍBRIDOS DE MILHO SOB DOIS NÍVEIS DE TECNOLOGIA NA REGIÃO CENTRAL DE MINAS GERAIS ${ }^{1}$
}

\author{
FÁBIO ANDRADE PADILHA², ÁLVARO VILELA DE RESENDE ${ }^{3}$, \\ SILVINO GUIMARÃES MOREIRA ${ }^{4}$, LAURO JOSÉ MOREIRA GUIMARÃES ${ }^{3}$, \\ PAULO EVARISTO OLIVEIRA GUIMARÃES ${ }^{3}$, ANTÔNIO CARLOS DE OLIVEIRA ${ }^{3}$
}

\author{
${ }^{l}$ Parte da Dissertação de Mestrado do primeiro autor no PPGCA/UFSJ. \\ ${ }^{2}$ Codevasf. Montes Claros, MG, Brasil,fabio.padilha@codevasf.gov.br \\ ${ }^{3}$ Embrapa Milho e Sorgo, Sete Lagoas, MG, Brasil, alvaro.resende@embrapa.br, \\ lauro.guimaraes@embrapa.br,paulo.guimaraes@embrapa.br,antoniocarlos.oliveira@embrapa.br \\ ${ }^{4}$ UFSJ, Sete Lagoas, MG, Brasil,silvino@ufsj.edu.br
}

Revista Brasileira de Milho e Sorgo, v.14, n.2, p. 207-218, 2015

\begin{abstract}
RESUMO - A determinação do potencial de rendimento de híbridos de milho em condições distintas de uso de tecnologia fornece subsídios para a melhoria do manejo da cultura. O objetivo deste trabalho foi avaliar o desempenho de híbridos de milho experimentais e comerciais em dois ambientes com distintos níveis de tecnologia em práticas de manejo agronômico, na região de Sete Lagoas, MG. Os dois ambientes diferenciaram-se em relação ao manejo do solo com adubos verdes, níveis de adubação mineral, uso de produtos para tratamento de sementes, adubações foliares e uso de pulverização com fungicidas. Foram comparados cinco híbridos experimentais e um comercial da Embrapa, além de quatro híbridos comerciais da iniciativa privada. Em cada ambiente, utilizou-se o delineamento experimental de blocos casualizados, com quatro repetições. Foram avaliados os componentes de produtividade por meio de análise de variância conjunta, a fim se verificar a existência de interação entre híbridos e ambientes de investimento tecnológico. Observou-se um incremento médio ao redor de $2 \mathrm{t} \mathrm{ha}^{-1} \mathrm{em}$ produtividade de grãos quando os híbridos foram cultivados com alto investimento tecnológico. Os híbridos 1I 862, 1I 873, AG 8088 YH e P 30F53 YH foram os de melhor desempenho, tanto no ambiente de médio quanto de alto nível tecnológico, com produtividades médias de 12,65 e 14,87 t ha ${ }^{-1}$, respectivamente.
\end{abstract}

Palavras-chave: alta produtividade; tratos culturais; posicionamento de cultivares; interação genótipo-ambiente; Zea mays.

\section{YIELD OF MAIZE HYBRIDS UNDER TWO LEVELS OF TECHNOLOGY IN THE CENTRAL REGION OF MINAS GERAIS STATE, BRAZIL}

\begin{abstract}
The determination of yield potential of maize hybrids under different technological conditions contributes to the improvement of crop management. The objective of this study was to evaluate the performance of experimental and commercial maize hybrids in two environments with different levels of technological investment in agronomic practices in the region of Sete Lagoas, Minas Gerais state. The two environments differed in relation to soil management with green manure, mineral fertilizer levels, use of products for seed treatment, foliar fertilization, and spraying with fungicides. Five experimental hybrids and one commercial hybrid from Embrapa, and four commercial hybrids of private companies were compared. In each environment, the yield components were evaluated in a randomized complete block design with four replications. Joint variance analysis was performed to verify the existence of interaction between hybrids and the technological environments. There was an average increment of approximately $2 \mathrm{tha}^{-1}$ in grain yield when hybrids were grown at high technological investment. The hybrids 1I 862, 1I 873, AG 8088 $\mathrm{YH}$, and P 30F53 YH exhibited superior performance in both environments, medium and high technological levels, with average yields of 12.65 and $14.87 \mathrm{tha}^{-1}$, respectively.
\end{abstract}

Key words: high yield; crop management; cultivar positioning; genotype-environment interaction; Zea mays. 
Para expressar seu potencial produtivo, o milho necessita de condições edafoclimáticas favoráveis, com atenção especial à fertilidade do solo, temperatura, disponibilidade hídrica e luminosidade. Adicionalmente, os ajustes de arranjo de plantas e tratos culturais interferem no rendimento de grãos da cultura. A necessidade de uma agricultura cada vez mais competitiva tem forçado a busca por contínuos ganhos de produtividade, com a elevação do nível tecnológico dos produtores de milho. Assim, têm-se encontrado com frequência lavouras na região do Cerrado com rendimento acima de $12 \mathrm{t} \mathrm{ha}^{-1}$ de grãos.

A utilização dos sistemas de manejo caracterizados pelo uso de irrigação, maiores aportes de fertilizantes, incremento na densidade de plantas, redução do espaçamento entre linhas, controle adequado de pragas, plantas daninhas e doenças constitui estratégia que pode contribuir para elevar o rendimento de grãos de milho num determinado local (Sangoi et al., 2006a). Dessa forma, a adequada combinação desses fatores pode maximizar a exploração dos recursos de cada ambiente, otimizando a produtividade da cultura de forma sustentável (Argenta et al., 2003).

O aumento do rendimento de grãos de milho está intimamente ligado ao seu potencial genético. Segundo Bison (2003), a obtenção de cultivares híbridas foi o principal causador do notável aumento da produtividade de grãos da cultura, possibilitando atender à demanda crescente por esse cereal observada no último século. O desafio dos melhoristas consiste em continuar produzindo novos híbridos que possam substituir com vantagens os existentes. Assim, temse buscado selecionar híbridos em ambientes de alto potencial produtivo, objetivando, com isso, identificar cultivares mais responsivas e com estabilidade de produção.

Adequar o tipo de cultivar ao nível tecnológico empregado nas propriedades contribui significativamente com a melhoria na eficiência de produção das culturas (Sangoi et al., 2006b), uma vez que as características genéticas das cultivares podem interferir na eficiência de utilização dos recursos do meio (Borém, 1999). Portanto, a avaliação de híbridos em diferentes ambientes é importante para que as empresas produtoras de sementes possam melhor posicionar suas cultivares nos diferentes sistemas de cultivo, em relação aos níveis de investimento tecnológico adotados pelos agricultores. Por outro lado, a agregação de novas tecnologias de manejo da cultura pode desencadear avanços com ganho de eficiência para o sistema de produção praticado numa dada região.

O presente trabalho teve como objetivo avaliar o desempenho de híbridos de milho experimentais e comerciais em dois ambientes de produção, estabelecidos com níveis de investimento tecnológico diferenciados em práticas de manejo cultural, na região Central de Minas Gerais.

\section{Material e Métodos}

O trabalho foi conduzido na Embrapa Milho e Sorgo, em Sete Lagoas, MG, localizada a 19²8'30" de latitude S, $44^{\circ} 15^{\prime} 08^{\prime \prime}$ de longitude $\mathrm{W}$ e $732 \mathrm{~m}$ de altitude. A área experimental é constituída de Latossolo Vermelho distroférrico muito argiloso (Sistema, 1999) e vinha sendo utilizada sob plantio direto, na sequência soja, milho e soja no verão dos anos agrícolas de 2009/2010, 2010/2011 e 2011/2012, respectivamente, com pousio nas entressafras. As condições médias de fertilidade do solo, antes da 
instalação do experimento, eram as seguintes: $\mathrm{pH}$ em água igual a 6,1; $\mathrm{Al}, \mathrm{Ca}, \mathrm{Mg}$ e $\mathrm{T}$ correspondendo a 0,$0 ; 4,5 ; 1,2$; e $10,7 \mathrm{cmol}_{\mathrm{c}} \mathrm{dm}^{-3}$; P e K pelo extrator Mehlich iguais a 16 e $96 \mathrm{mg} \mathrm{dm}^{-3}$; V de 55\%; e teores de argila e matéria orgânica iguais a 660 e 34 $\mathrm{g} \mathrm{kg}^{-1}$.

O estudo consistiu da avaliação de dez híbridos de milho para produção de grãos, em ambientes com dois níveis de tecnologias na cultura, considerando alto e médio investimentos. Foram comparados cinco híbridos simples experimentais (1I 862, 1I 873, 1 I 923, 1I 931, 1I 953) e um híbrido simples comercial (BRS 1055) da Embrapa, todos não transgênicos, e quatro híbridos simples transgênicos comerciais de empresas privadas (AG 8088 YH, DKB 390 VTpro, P 3646 H, P 30F53 YH).

Para cada ambiente, o delineamento experimental foi em blocos completos casualizados com quatro repetições, sendo cada parcela constituída de oito linhas de $6 \mathrm{~m}$ de comprimento, espaçadas em $50 \mathrm{~cm}$. Como parcela útil, consideraram-se três das linhas centrais, deixando-se $1 \mathrm{~m}$ nas extremidades como bordadura.

Para iniciar o estabelecimento do ambiente de alto investimento tecnológico (Tabela 1), em agosto de 2012 foram feitas aplicações a lanço de $100 \mathrm{~kg}$ $\mathrm{ha}^{-1}$ de superfosfato simples, $200 \mathrm{~kg} \mathrm{ha}^{-1}$ de cloreto de potássio, $429 \mathrm{~kg} \mathrm{ha}^{-1}$ de óxido de magnésio e $50 \mathrm{~kg} \mathrm{ha}^{-1}$ de FTE BR 10, com o objetivo de elevar a condição de fertilidade em relação aos macro e micronutrientes contidos nestas fontes. Após a aplicação desses fertilizantes, fez-se uma subsolagem a cerca de $25 \mathrm{~cm}$ de profundidade. Posteriormente, em setembro de 2012, foi realizado o cultivo irrigado de crotalária e milheto consorciados como plantas de cobertura, objetivando produção de biomassa (palhada) e adubação verde. Quarenta e seis dias após o plantio das culturas de cobertura, foram efetuadas dessecação e corte, mantendo-se a palhada sobre o solo.

Para o ambiente de médio nível tecnológico, as sementes de milho foram tratadas de forma tradicional, com uma solução contendo fungicida Metalaxyl-M + Fludioxonil, inseticida Bifenthrin, corante e água. Já para o ambiente de alto nível tecnológico, utilizou-se a mesma solução descrita acima, acrescida do fungicida Thiram + Carboxin e do inseticida Thiamethoxam, além de uma solução fertilizante com Cobalto + Molibdênio e um bioestimulante à base de Giberelina + Auxina + Citocinina (Tabela 1). O tratamento das sementes foi feito no dia anterior à semeadura.

A adubação de base foi feita com a aplicação, no sulco de semeadura, de 260 e $500 \mathrm{~kg} \mathrm{ha}^{-1}$ do formulado NPK 08-28-16 para os ambientes de médio e alto investimentos, respectivamente (Tabela 1), conforme regulagens disponíveis na semeadora que foi utilizada para essa finalidade. Os híbridos de milho foram semeados manualmente em sulcos abertos sobre as linhas de adubação, com espaçamento de $50 \mathrm{~cm}$ entre linhas e densidade equivalente a 75 mil sementes ha-1, no dia 31 de outubro de 2012. No período de 20/10/2012 a 20/03/2013, a precipitação acumulada alcançou $577 \mathrm{~mm}$, mas, dada a distribuição irregular das chuvas (Figura 1), utilizou-se irrigação complementar em determinados momentos do cultivo.

Dez dias após a semeadura, foi feita a aplicação de Atrazina, Tembotriona e óleo vegetal para o controle de plantas invasoras. Em ambos os ambientes e para todos os híbridos (transgênicos ou não), foram feitas três aplicações de inseticidas para controle de lagartas, em V2 (duas folhas expandidas com o colar visível, conforme escala indicada por Magalhães \& Durães, 


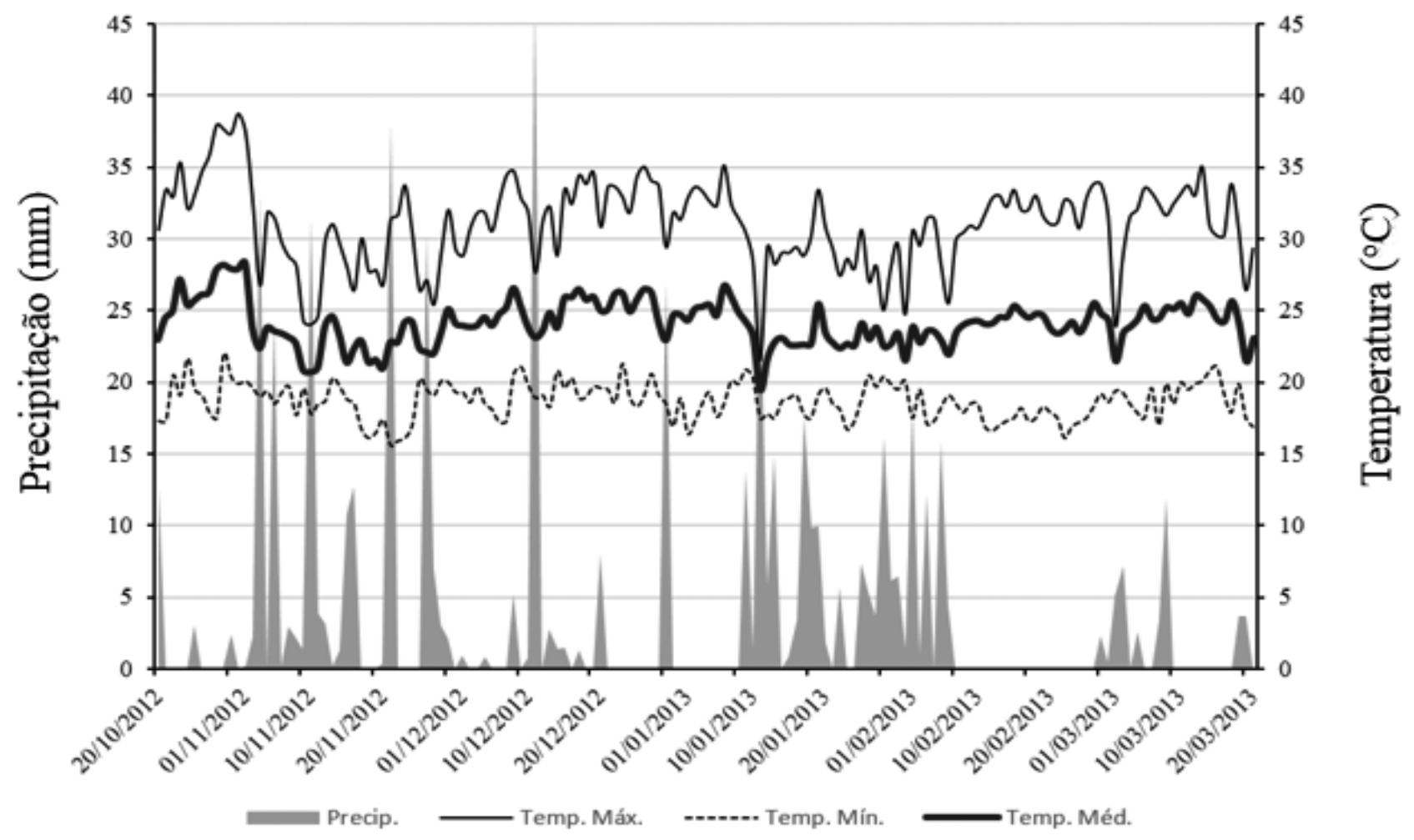

FIGURA 1. Condições de temperatura e distribuição da precipitação pluviométrica durante a safra 2012-2013 na Embrapa Milho e Sorgo, Sete Lagoas, MG.

2006), V5 e V6, com produtos à base de Metomil, Cipermetrina e Metomil, respectivamente (Tabela 1).

No ambiente de médio investimento, foi realizada apenas uma adubação de cobertura em V4 com $200 \mathrm{~kg} \mathrm{ha}^{-1}$ de ureia (45\% de N), distribuídos em filete nas entrelinhas. No ambiente de alto investimento, além dessa primeira cobertura, efetuaram-se mais duas adubações, com $350 \mathrm{~kg} \mathrm{ha}^{-1}$ de formulado NPK 20-00-20 em V5 e $200 \mathrm{~kg} \mathrm{ha}^{-1}$ de sulfato de amônio (20\% de N e $24 \%$ de S) em V6. Nesse ambiente, foram feitas também pulverizações com um fertilizante foliar (14\% de N; 6,0\% de $\mathrm{P}_{2} \mathrm{O}_{5} ; 4,0 \%$ de $\mathrm{K}_{2} \mathrm{O} ; 0,1 \%$ de B; $1,0 \%$ de $\mathrm{Mn} ; 0,05 \%$ de Mo; e 5,0\% de $\mathrm{Zn}$ ) em V5 e outro $\left(1,73 \%\right.$ de $\mathrm{N} ; 5,0 \%$ de $\mathrm{K}_{2} \mathrm{O} ; 2,1 \%$ de $\mathrm{S}$; $0,08 \%$ de B; $0,49 \%$ de Fe; $1,0 \%$ de $\mathrm{Mn} ; 2,45 \%$ de $\mathrm{Zn}$; e 3,5\% de carbono orgânico) em V7. Ainda no am- biente de alto investimento tecnológico, foram feitas duas aplicações preventivas de fungicidas, em V8 com Azoxystrobin + Ciproconazol, e no pré-florescimento (V18) com Piraclostrobina + Epoxiconazol (Tabela 1). Após a maturação fisiológica, foi realizada a colheita das três linhas de $4 \mathrm{~m}$ de comprimento na área útil das parcelas. Foram feitas avaliações de estande final, número de espigas, número de grãos por espiga e peso de 100 grãos. O número de grãos por espiga foi estimado a partir de uma amostra de cinco espigas por parcela, das quais foram contados o número de fileiras e o número de grãos de duas fileiras. Após a debulha, determinou-se a produtividade de grãos corrigida para $13 \%$ de umidade.

Osdados foramsubmetidosaanálisede variância conjunta para verificar a existência de interação entre 


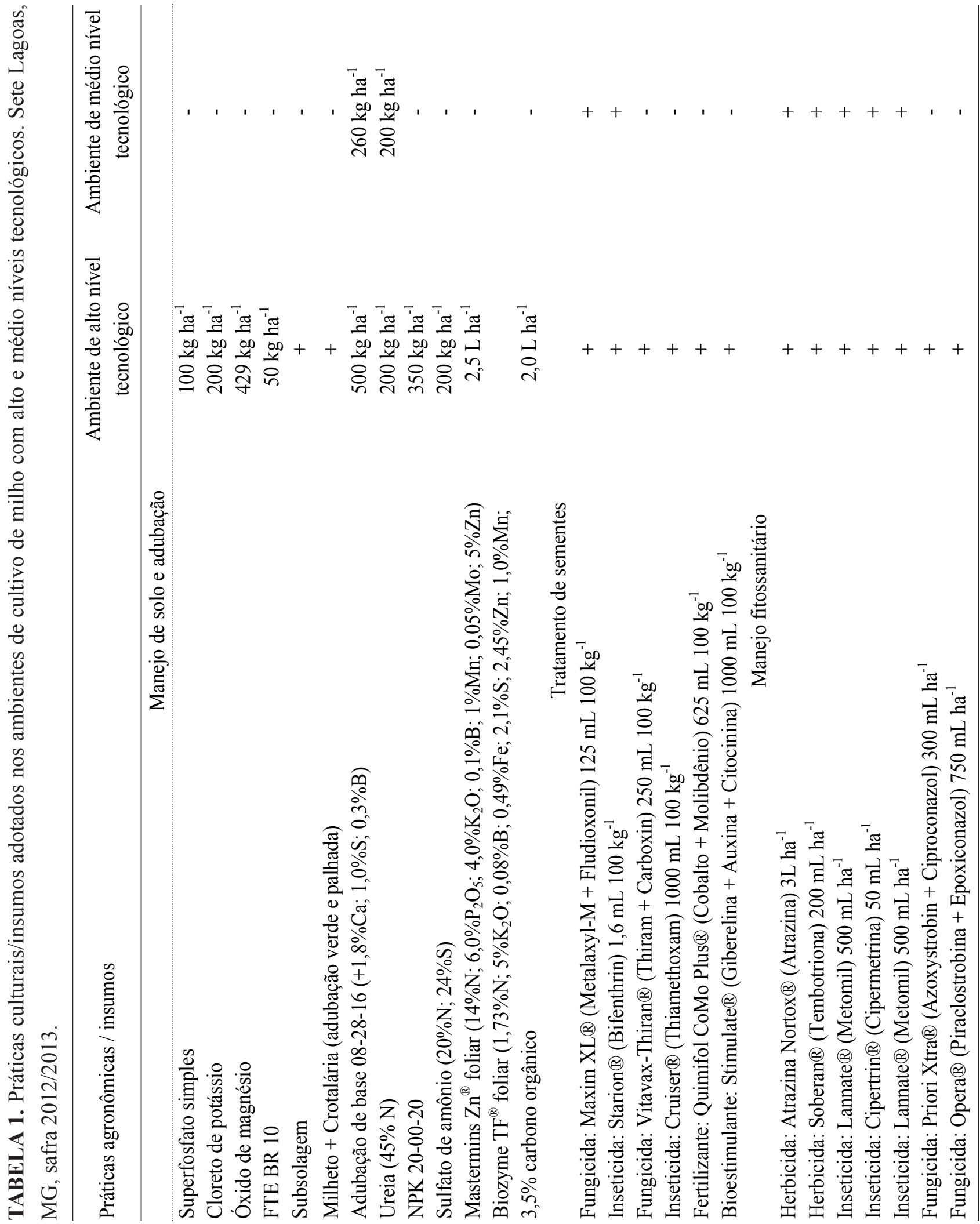


híbridos e ambientes (níveis tecnológicos). Utilizouse o teste de agrupamento de médias de Scott-Knott, a $5 \%$ de probabilidade, para a comparação de tratamentos. Todas as análises estatísticas foram realizadas empregando-se o programa Sisvar (Ferreira, 2011).

\section{Resultados e Discussão}

As produtividades obtidas de acordo com as combinações de tratamentos variaram de 10.632 a $15.187 \mathrm{~kg} \mathrm{ha}^{-1}$ de grãos (Tabela 2). Verificaram-se efeitos isolados de híbridos e de ambientes de cultivo, sem haver interação significativa. Assim, observam-se diferenças entre os híbridos, mas a ordem de posicionamento é praticamente a mesma nos dois níveis tecnológicos. A melhoria da fertilidade do solo, associada às práticas diferenciadas de tratamento de sementes, adubação foliar e pulverização de fungicida no ambiente de alto investimento tecnológico, proporcionaram produtividades superiores em relação ao ambiente de médio investimento. Em princípio, a pulverização de fungicida seria desnecessária, uma vez que não se constatou incidência relevante de doenças. Na média dos híbridos, a diferença de produtividade entre os ambientes foi de $2 \mathrm{t} \mathrm{ha}^{-1}$. Resultados semelhantes foram encontrados por Sangoi et al. (2006b), ao constatarem que investimentos crescentes em práticas de manejo resultaram em aumento no rendimento de grãos de cultivares de milho nos estados de Santa Catarina e Rio Grande do Sul.

Merece destaque o fato de que as plantas de milho cultivadas sob maior nível tecnológico anteciparam em dois dias os florescimentos masculino e feminino em relação àquelas que se desenvolveram no ambiente de média tecnologia. Uma maior precocidade, sem perda de potencial produtivo, é situação desejável em condições de lavoura, pois acaba por constituir-se num fator de redução de risco da cultura.

Os híbridos com melhor desempenho foram 1I 862, 1I 873, AG 8088 YH e P 30F53 YH, com produtividades acima de $13.000 \mathrm{~kg} \mathrm{ha}^{-1}$ na média dos dois níveis tecnológicos. Entretanto, em termos absolutos, os híbridos 1I 873, AG 8088 YH e P 30F53 YH alcançaram produtividades superiores a $15.000 \mathrm{~kg} \mathrm{ha}^{-1}$ no ambiente de alto investimento (Tabela 2). Esses resultados demonstram o elevado potencial produtivo desses híbridos, num patamar ainda não relatado para as condições de Sete Lagoas, e reforçam a possibilidade de se buscarem novas metas de produtividade em lavouras irrigadas nas condições edafoclimáticas da região Central de Minas Gerais. Essa região apresenta um histórico de produtividades mais limitadas em relação a outras áreas agrícolas do país, em parte por não possuir as condições ideais de altitude e temperatura para a cultura do milho.

Cruz et al. (2005) compararam 24 cultivares nas safras 2003/2004 e 2004/2005, em três experimentos conduzidos na região de Sete Lagoas, buscando obter densidade de 60.000 plantas por hectare. A variação das produtividades obtidas nos três experimentos foi, respectivamente, de 6.881 a $10.358,2.948$ a 8.778 e 3.521 a 7.750 , sendo nos três casos o maior rendimento associado à cultivar DKB 390. Ao se considerar o desempenho dessa cultivar na sua versão transgênica VTpro e de outros híbridos que a superaram no presente estudo (Tabela 2), comprova-se o ganho de potencial produtivo pelo contínuo desenvolvimento de novos genótipos, associado ao investimento em tecnologias de manejo da cultura.

Mesmo sob menor nível tecnológico (Tabela 2), foi elevada a produtividade média dos híbridos (11.967 $\mathrm{kg} \mathrm{ha}^{-1}$ ), em especial quando comparada aos dados médios do Brasil e do estado de Minas Gerais na safra 2012/2013, que foram de 5.874 e $5.149 \mathrm{~kg}$ 


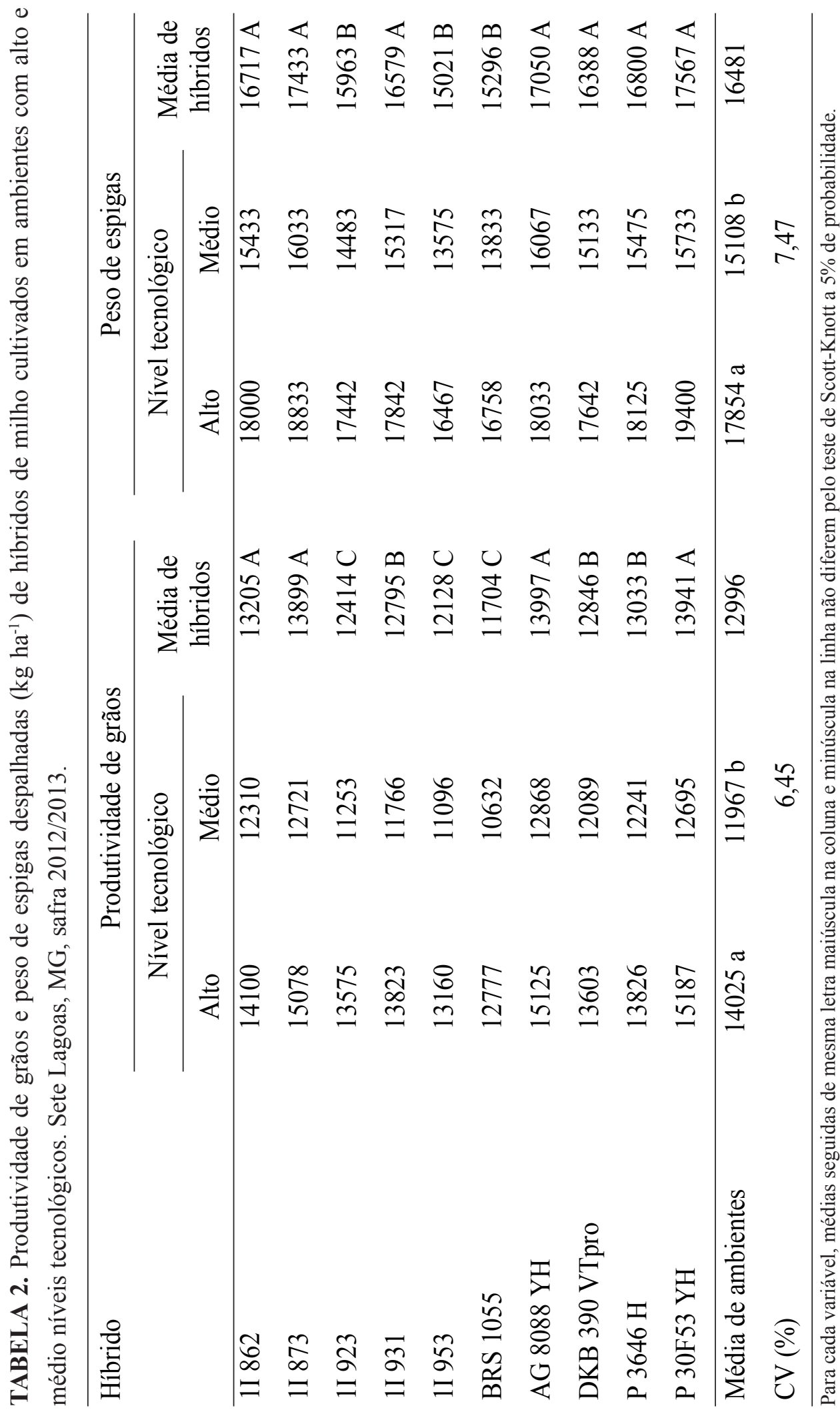


ha $^{-1}$, respectivamente (CONAB, 2014). A produtividade média do ambiente com alto nível tecnológico (14.025 $\left.\mathrm{kg} \mathrm{ha}^{-1}\right)$ foi maior que a das cultivares avaliadas no Ensaio Nacional de Cultivares de Milho na safra 2011/2012 em Sete Lagoas, superando inclusive o melhor material, BMX 1105, que produziu 13.611 $\mathrm{kg} \mathrm{ha}^{-1}$ (Rocha, 2012).

Dois híbridos experimentais da Embrapa Milho e Sorgo apresentaram médias estatisticamente iguais às cultivares de empresas privadas com grande participação no mercado de sementes. O híbrido experimental 1I 873 produziu mais de $15.000 \mathrm{~kg} \mathrm{ha}^{-1}$ sob alto investimento tecnológico, o que o qualificaria para possível lançamento comercial, considerando o aspecto de potencial de rendimento de grãos nas condições deste experimento (Tabela 2).

$\mathrm{Na}$ avaliação dos componentes de produção, obteve-se interação significativa entre híbridos e ambientes de investimento tecnológico para a variável estande final de plantas. Contudo, na maioria dos híbridos, o estande não diferiu em função do nível tecnológico, fazendo com que as médias dos dois ambientes se igualassem (Tabela 3). É interessante destacar que o estande médio dos materiais da Embrapa tendeu a ser menor que a média das cultivares das outras empresas, com valores de 68.970 e 71.719 plantas ha ${ }^{-1}$, respectivamente. Cabe ponderar que cinco dos híbridos da Embrapa são materiais experimen-

TABELA 3. Estande final (plantas $\mathrm{ha}^{-1}$ ) de híbridos de milho cultivados em ambientes com alto e médio níveis tecnológicos. Sete Lagoas, MG, safra 2012/2013.

\begin{tabular}{lccc}
\hline Híbrido & \multicolumn{2}{c}{ Nível tecnológico } & Média de \\
\cline { 2 - 3 } & Alto & Médio & $65729 \mathrm{D}$ \\
\hline 1 II 862 & $63958 \mathrm{Cb}$ & $67500 \mathrm{Ca}$ & $71667 \mathrm{~B}$ \\
1 I 873 & $73333 \mathrm{Aa}$ & $70000 \mathrm{Bb}$ & $70592 \mathrm{~B}$ \\
1 I 923 & $70977 \mathrm{Aa}$ & $70208 \mathrm{Ba}$ & $72916 \mathrm{~A}$ \\
1I 931 & $72917 \mathrm{Aa}$ & $72917 \mathrm{Aa}$ & $67813 \mathrm{C}$ \\
1I 953 & $68125 \mathrm{Ba}$ & $67500 \mathrm{Ca}$ & $65104 \mathrm{D}$ \\
BRS 1055 & $63333 \mathrm{Cb}$ & $66875 \mathrm{Ca}$ & $72396 \mathrm{~A}$ \\
AG 8088 YH & $72500 \mathrm{Aa}$ & $72292 \mathrm{Aa}$ & $71042 \mathrm{~B}$ \\
DKB 390 VTpro & $71042 \mathrm{Aa}$ & $71042 \mathrm{Ba}$ & $72917 \mathrm{~A}$ \\
P 3646 H & $72708 \mathrm{Aa}$ & $73125 \mathrm{Aa}$ & $70521 \mathrm{~B}$ \\
P 30F53 YH & $71667 \mathrm{Aa}$ & $69375 \mathrm{Ca}$ & 70070 \\
\hline Média de ambientes & 70056 & 70083 & \\
\hline CV (\%) & & 2,50 & \\
\hline
\end{tabular}

Para cada variável, médias seguidas de mesma letra maiúscula na coluna e minúscula na linha não diferem pelo teste de Scott-Knott a $5 \%$ de probabilidade. 
tais, cujos procedimentos de produção de sementes em pequenas quantidades não contemplam os protocolos utilizados em escala comercial para garantia de padrão e vigor dos produtos a serem entregues ao agricultor. Esse fator pode ter influenciado tal diferença de estande.

O conjunto de tratos culturais adotado no ambiente de maior nível tecnológico influenciou positivamente alguns dos componentes de produção do milho, a exemplo do peso de espigas despalhadas (Tabela 2). Houve ainda variação significativa do peso de espigas das cultivares na média dos ambientes, sendo que os três híbridos mais produtivos renderam acima de $17.000 \mathrm{~kg} \mathrm{ha}^{-1}$ de espigas. Em parte, isso provavel- mente se deve aos maiores comprimento e diâmetro das espigas e peso dos sabugos. Gonçalves Jr. et al. (2008) observaram incremento significativo no peso médio do sabugo quando as doses de $\mathrm{N}: \mathrm{P}_{2} \mathrm{O}_{5}: \mathrm{K}_{2} \mathrm{O}$ foram aumentadas de 30:100:50 para 60:200:100 $\mathrm{kg} \mathrm{ha}^{-1}$. Machado et al. (2008), avaliando híbridos em 15 ambientes na região Sul de Minas Gerais, constataram boa relação entre peso de espigas e produtividade de grãos, como também verificado no presente estudo $(\mathrm{r}=0,97 * *)$.

Para o número de espigas, constataram-se efeitos significativos para híbridos, ambientes de investimento tecnológico e a interação híbridos x ambientes. O híbrido 1I 923 foi o que produziu maior número de espigas por hectare (Tabela 4). No entanto,

TABELA 4. Número de espigas (espigas ha-1) e índice de espigas (espigas planta-1) de híbridos de milho cultivados em ambientes com alto e médio níveis tecnológicos. Sete Lagoas, MG, safra 2012/2013.

\begin{tabular}{|c|c|c|c|c|}
\hline \multirow{3}{*}{ Híbrido } & \multicolumn{3}{|c|}{ Número de espigas } & \multirow{3}{*}{$\begin{array}{l}\text { Média de índice de } \\
\text { espigas }\end{array}$} \\
\hline & \multicolumn{2}{|c|}{ Nível tecnológico } & \multirow{2}{*}{$\begin{array}{l}\text { Média de } \\
\text { híbridos }\end{array}$} & \\
\hline & Alto & Médio & & \\
\hline 1 I 862 & $88750 \mathrm{Ba}$ & $85000 \mathrm{Ba}$ & $86875 \mathrm{~B}$ & $1,3 \mathrm{~B}$ \\
\hline 1I 873 & $78750 \mathrm{Ca}$ & $79167 \mathrm{Ca}$ & $78958 \mathrm{C}$ & $1,1 \mathrm{D}$ \\
\hline 1I 923 & $108333 \mathrm{Aa}$ & $93750 \mathrm{Ab}$ & $101042 \mathrm{~A}$ & $1,4 \mathrm{~A}$ \\
\hline 1I 931 & $89167 \mathrm{Ba}$ & $81250 \mathrm{Cb}$ & $85208 \mathrm{~B}$ & $1,2 \mathrm{C}$ \\
\hline 1I 953 & $76667 \mathrm{Ca}$ & $72917 \mathrm{Ca}$ & $74792 \mathrm{C}$ & $1,1 \mathrm{D}$ \\
\hline BRS 1055 & $81250 \mathrm{Ca}$ & $72083 \mathrm{Cb}$ & $76667 \mathrm{C}$ & $1,2 \mathrm{C}$ \\
\hline AG $8088 \mathrm{YH}$ & $78750 \mathrm{Ca}$ & $74583 \mathrm{Ca}$ & $76667 \mathrm{C}$ & $1,1 \mathrm{D}$ \\
\hline DKB 390 VTpro & $73333 \mathrm{Ca}$ & $76250 \mathrm{Ca}$ & $74792 \mathrm{C}$ & $1,1 \mathrm{D}$ \\
\hline P $3646 \mathrm{H}$ & $78333 \mathrm{Ca}$ & $79583 \mathrm{Ca}$ & $78958 \mathrm{C}$ & $1,1 \mathrm{D}$ \\
\hline P 30F53 YH & $76250 \mathrm{Ca}$ & $77083 \mathrm{Ca}$ & $76667 \mathrm{C}$ & $1,1 \mathrm{D}$ \\
\hline Media de ambientes & $82958 \mathrm{a}$ & $79167 \mathrm{~b}$ & 81062 & 1,2 \\
\hline
\end{tabular}

Médias seguidas de mesma letra maiúscula na coluna e minúscula na linha não diferem pelo teste de Scott-Knott a 5\% de probabilidade. 
isso não se refletiu em maior produtividade de grãos, uma vez que esse híbrido não foi agrupado entre os mais produtivos. Sua maior prolificidade não foi um fator favorável, pois as espigas produzidas foram pequenas e de baixo peso, o que pode ter sido decorrente de menor adaptação ao arranjo de plantas empregado,

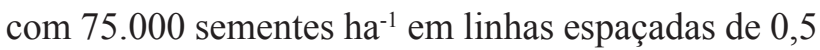
m. Por sua vez, a maioria dos híbridos mais produtivos (1I 873, AG 8088 YH e P 30F53 YH) tendeu a apresentar menor índice de espigas, evidenciando a falta de relação do número de espigas com a produtividade de grãos no presente estudo $(r=0,11)$.

O número de grãos por espiga variou conforme a cultivar, mas não foi afetado pelos níveis tecnológicos e apresentou pouca relação com a produtividade (Tabela 5). Tal resultado diverge dos obtidos nos trabalhos de Gonçalves Jr. et al. (2008), que verificaram aumento na quantidade de grãos por espiga e no peso de grãos com a elevação do nível de adubação, e de Balbinot Jr. et al. (2005), que constataram que as cultivares de maior produtividade possuíam número mais elevado de grãos por fileira nas espigas.

Para o peso de 100 grãos, houve significância da interação entre híbridos e ambientes de investimento tecnológico, bem como para esses fatores isoladamente (Tabela 5). As médias de peso de 100 grãos nos ambientes de alto e médio níveis tecnológicos foram de 34,5 g e 31,7 g, respectivamente. Na interação, apenas duas cultivares não apresentaram aumento no peso de 100 grãos devido ao maior nível tecnológico (Tabela 5). Assim, a combinação de aporte extra de nutrientes e tratos culturais diferenciados no ambiente de alto investimento resulta em incremento do peso de 100 grãos. Argenta et al. (2003) relataram que os valores para peso de 100 grãos foram maiores nos sistemas destinados a potencializar o rendimento da cultura do milho. Contudo, apesar das diferenças ob- servadas entre cultivares em cada ambiente, a variável peso de 100 grãos não se mostrou fortemente relacionada à produtividade no presente estudo $(\mathrm{r}=0,29)$.

Numa análise global, verifica-se que as condições do ambiente de cultivo, determinadas pelo nível de investimento em práticas de manejo agronômico atualmente disponíveis, influenciam o desempenho produtivo de híbridos de milho e os componentes de produção. O estabelecimento de um ambiente favorável a partir do incremento no fornecimento de nutrientes conjugado com outras práticas culturais modernas e a utilização de híbridos de ponta permitem alcançar novos patamares produtivos em regiões antes consideradas menos vocacionadas para a cultura do milho de alto rendimento, como no caso da região Central de Minas Gerais.

\section{Conclusões}

Há incremento médio ao redor de $2 \mathrm{t} \mathrm{ha}^{-1} \mathrm{em}$ produtividade de grãos quando os híbridos são cultivados com alto nível tecnológico.

Os híbridos 1I 862, 1I 873, AG 8088 YH e P 30F53 YH apresentam melhor desempenho tanto no ambiente de médio quanto de alto nível tecnológico, com produtividades médias de 12,65 e 14,87 t ha-1, respectivamente.

Dentre os componentes de produção, o peso de espigas é o mais relacionado à produtividade de grãos.

O cultivo de milho com maior nível tecnológico permite obter alto rendimento de grãos, mesmo em menor altitude, como na região de Sete Lagoas, MG.

\section{Agradecimentos}

À Fapemig e ao CNPq, pela concessão de bolsas de iniciação científica. 


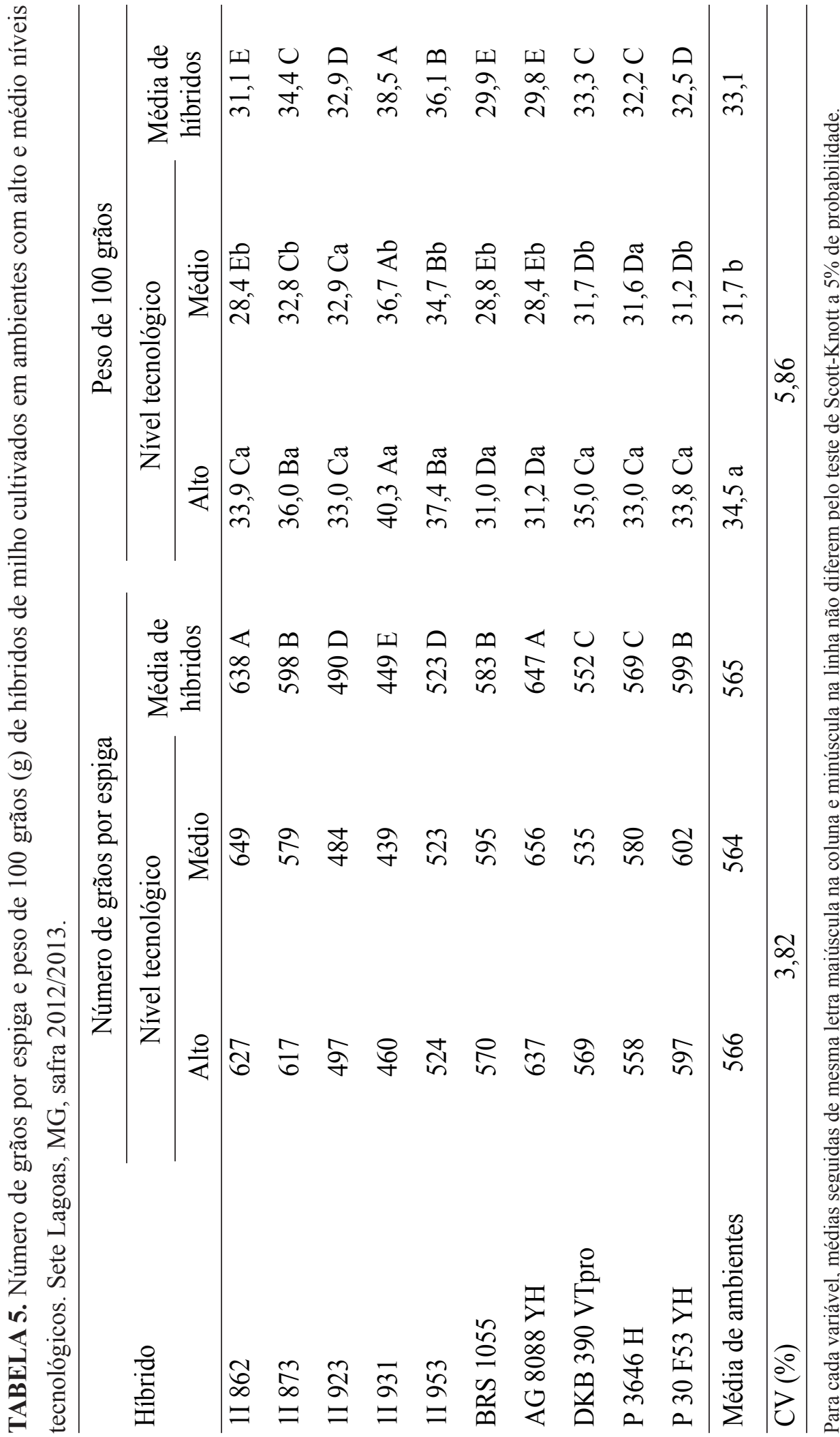




\section{Referências}

ARGENTA, G.; SANGOI, L.; SILVA, P. R. F. da; RAMPAZZO,C.;GRACIETTI,L.C.STRIEDER, M. L. FORSTHOFER, E. L.; SUHRE, E. Potencial de rendimento de grãos de milho em dois ambientes e cinco sistemas de produção.

Ciência Agrária, Curitiba, v. 4, p. 27-34, 2003. BALBINOT JÚNIOR, A. A.; BACKES, R. L.; ALVES, A. C.; OGLIARI, J. B.; FONSECA, J. A. da. Contribuição de componentes de rendimento na produtividade de grãos em variedades de polinização aberta de milho. Revista Brasileira Agrociências, Pelotas, v. 11, n. 2, p. 161-166, 2005. BISON, O.; RAMALHO, M. A. P.; RAPOSO, F. V. Potencial de híbridos simples de milho para extração de linhagens. Ciências Agrotécnica, Lavras, v. 27, n. 2, p. 348-355, 2003.

BORÉM, A. Melhoramento de espécies cultivadas. Viçosa: UFV, 1999. 817 p.

CONAB - COMPANHIA NACIONAL DE ABASTECIMENTO, Acompanhamento de safras brasileiras. Disponível em: < http:// www.conab.gov.br/OlalaCMS/uploads/ arquivos/14_07_09_09_36_57_10_levantamento_ de_graos_julho_2014.pdf $>$. Acessado em: 3 jul. 2014.

CRUZ, J. C.; MONTEIRO, M. A. R.; LOUREIRO, J. E.; PEREIRA FILHO, I. A.; NOCE, M. A.; VIANA, A. C.; ALBERNAZ, W. M. Avaliação de Cultivares de Milho na Região de Sete Lagoas, MG. Sete Lagoas:Embrapa Milho e Sorgo, 2005.6 p. (Embrapa Milho e Sorgo. Circular Técnica, 65). FERREIRA, D. F. Sisvar: a computer statistical analysis system. Ciência e Agrotecnologia, Lavras, v. 35, n. 6, p. 1039-1042, 2011.
GONÇALVES JÚNIOR, A. C.; NACKE, H.; STREY, L.; SCHWANTES, D.; SELZLEIN, C. Produtividade e componentes da produção do milho adubado com $\mathrm{Cu}$ e NPK em um argissolo. ScientiaAgrária,Curitiba,v.9,n.1,p.35-40,2008. MACHADO, J. C.; SOUZA, J. C. de; RAMALHO, M. A. P.; LIMA, J. L. Estabilidade de produção de híbridos simples e duplos de milho oriundos de um mesmo conjunto gênico. Bragantia, Campinas, v. 67, n. 3, p. 627-631, 2008.

MAGALHÃES, P. C.; DURAES, F. O. M. Fisiologia da produção de milho. Sete Lagoas: Embrapa Milho e Sorgo, 2006. 10 p. (Embrapa Milho e Sorgo. Circular Técnica, 76).

ROCHA, L. M. P. da (Coord.). Ensaio Nacional de Cultivares de Milho Centro Precoce 2011/2012. Sete Lagoas: Embrapa Milho e Sorgo, 2012. 35 p. Disponível em: <http:// www.cnpms.embrapa.br/ensaio/ensaio2012/ AnaliseCentrop/centrop.php>. Acessado em: 4 ago. 2014.

SANGOI, L.; ERNANI, P. R.; SILVA, P. R. F. da; HORN, D.; SCHMITT, A.; SCHWEITZER, C. Desempenho agronômico de cultivares de milho em quatro sistemas de manejo. Revista Brasileira de Milho e Sorgo, Sete Lagoas, v. 5, n. 2, p. 218-231, 2006.b

SANGOI, L.; ERNANI, P. R.; SILVA, P. R. F. da; HORN, D.; SCHMITT, A.; SCHWEITZER, C.; MOTTER, F. Rendimento de grãos e margem bruta de cultivares de milho com variabilidade genética contrastante em diferentes sistemas de manejo. Ciência Rural, Santa Maria, v. 36, n. 3, p. 747-755, 2006a.

SISTEMA Brasileiro de Classificação de Solos. Brasília, DF: Embrapa Produção de Informação; Rio de Janeiro: Embrapa Solos, 1999. 412 p. 